\title{
Reduced graphene oxide-based field effect transistors for the detection of E7 protein of human papillomavirus in saliva
}

\author{
Patrik Aspermair ${ }^{1,2,3} \cdot$ Vladyslav Mishyn $^{1} \cdot$ Johannes Bintinger ${ }^{3} \cdot$ Henri Happy $^{1} \cdot$ Komal Bagga $^{4}$. \\ Palaniappan Subramanian ${ }^{5} \cdot$ Wolfgang Knoll $^{2,3} \cdot$ Rabah Boukherroub $^{1} \cdot$ Sabine Szunerits ${ }^{1}$
}

Received: 4 June 2020 / Revised: 23 July 2020 / Accepted: 12 August 2020 / Published online: 20 August 2020

(C) Springer-Verlag GmbH Germany, part of Springer Nature 2020

\begin{abstract}
Several challenging biological sensing concepts have been realized using electrolyte-gated reduced graphene oxide field effect transistors (rGO-FETs). In this work, we demonstrate the interest of rGO-FET for the sensing of human papillomavirus (HPV), one of the most common sexually transmitted viruses and a necessary factor for cervical carcinogenesis. The highly sensitive and selective detection of the HPV-16 E7 protein relies on the attractive semiconducting characteristics of pyrene-modified rGO functionalized with RNA aptamer Sc5-c3. The aptamer-functionalized rGO-FET allows for monitoring the aptamer-HPV-16 E7 protein binding in real time with a detection limit of about $100 \mathrm{pg} \mathrm{mL}^{-1}(1.75 \mathrm{nM})$ for HPV-16 E7 from five blank noise signals (95\% confidence level). The feasibility of this method for clinical application in point-of-care technology is evaluated using HPV-16 E7 protein suspended in saliva and demonstrates the successful fabrication of a promising field effect transistor biosensor for HPV diagnosis.
\end{abstract}

Keywords Human papillomavirus (HPV) - Aptamer · Reduced graphene oxide (rGO) - Field effect transistors $\cdot$ Surface functionalization $\cdot$ Electronic biosensor $\cdot$ Point-of-care diagnostics

\section{Introduction}

The development of a field effect transistor (FET), allowing signal enhancement of biological binding events with an

Published in the topical collection 2D Nanomaterials for Electroanalysis with guest editor Sabine Szunerits.

Patrik Aspermair

Patrik.Aspermair@ait.ac.at

Sabine Szunerits

sabine.szunerits@univ-lille.fr

1 Univ. Lille, CNRS, Centrale Lille, Univ. Polytechnique Hauts-de-France, UMR 8520 - IEMN, 59000 Lille, France

2 CEST Competence Centre for Electrochemical Surface Technologies, Konrad-Lorenz-Strasse 24, 3430 Tulln, Austria

3 Biosensor Technologies, Austrian Institute of Technology, Konrad-Lorenz-Strasse 24, 3430 Tulln, Austria

4 Advanced Processing Technology Research Centre, School of Mechanical and Manufacturing Engineering, Dublin City University, Glasnevin, Dublin 9, Ireland

5 Department of Materials Engineering, KU Leuven, Kateelpark Arenberg, 3001 Heverlee, Belgium applied electric field, is a lab-on-a-chip approach with short assay times down to seconds in the best cases [1-4]. It represents an attractive sensing platform due to its fast response time, ease to use, possibility of miniaturization together with sensitive and selective detection. Selective sensing is achieved by anchoring specific probes on the conducting rGO channel of the transistor, which remains a critical factor for FET sensor performance, of particular importance when used as a biosensor. The golden standard of viral detection in clinical settings remains the polymerase chain reaction (PCR) or the advanced quantitative real-time reverse transcription PCR (qRT-PCR) $[5,6]$. The typical turnaround time for screening and diagnosing patients is $>24 \mathrm{~h}$. Additional drawback is the fact that the positive rate of qRT-PCR assays is often reported to vary from 30 to $60 \%$. Therefore, more accurate and sensitive methods are urgently needed to support the quality assurance of the qRT-PCR. In order to be applicable for viral infection diagnosis, the FET biosensor should have a sensitivity close to that of PCR, a lower per-test cost, and minimum investment in the necessary laboratory hardware. For these reasons, graphenebased FET sensors for viral infection screening are still at their early phase of development [4, 7-11]. The use of rGO-based FET for the evaluation of Ebola glycoproteins suspended in 
human serum and plasma with a sensitivity down to $1 \mathrm{ng} \mathrm{mL} \mathrm{mL}^{-1}$ was reported by Chen et al. [4]. The rapid detection of COVID-19 causative virus in the human nasopharynx was just reported on a graphene field effect transistor [11]. The sensor was produced by coating graphene sheets of the FET with specific antibodies against SARS-CoV-2 spike protein. Detection limits of $1 \mathrm{fg} \mathrm{mL}^{-1}$ in PBS and $100 \mathrm{fg} \mathrm{mL}^{-1}$ in universal transport medium (UMT) were achieved for the SARS-CoV-2 spike protein. Field effect biosensing with monoclonal antibodies covalently linked to graphene was proposed for the quantitative detection of native Zika virus (ZIKV), with a detection of antigen in buffer at concentrations as low as $450 \mathrm{pM}$ [9]. Additionally, good linearity and large dynamic range of label-free protein detection allow the use of graphene FETs as biosensors in a wide range of applications [12].

In this work, we investigate the potential of reduced graphene oxide-based FET (rGO-FET) for the detection of human papillomavirus (HPV) [13]. More than 100 types of human papillomaviruses (HPVs) have been identified and approximately half of them infect the genital tract. All papillomaviruses share a common genetic structure: a doublestranded circular DNA genome encoding approximately eight open reading frames (ORFs). As only $1 \%$ of the infected people present symptomatology, early diagnosis relies currently on molecular diagnosis tools, notably nucleic acid hybridization assays and PCR [14].

One of the first works on using a biosensor-based platform for HPV sensing is the electrochemical sensor proposed by the group of O'Sullivan for the detection of HPV-16 E6 DNA with a detection limit of $490 \mathrm{pM}$ [15]. One of the currently best performing HPV sensors is based on the use of HPV-16 DNA-modified AuNPs/single-walled carbon nanotubes with a detection limit of $1 \mathrm{aM}$ and a linear range between $1 \mathrm{aM}$ and $1 \mathrm{pM}$ for HPV-16 DNA [16]. Our group has recently demonstrated the interest of aptamer-modified electrodes for the sensitive and selective detection of the E7 major capsid protein of human papillomavirus (HPV) [17]. Here, we show that rGOFET with adapted surface architecture allows for the sensing of HPV-16 E7 protein, with a linear sensing regime between 30 and $1000 \mathrm{nM}$.

\section{Materials and methods}

Potassium hexacyanoferrate(II) $\left(\left[\mathrm{K}_{4} \mathrm{Fe}(\mathrm{CN})_{6}\right]\right)$, 3-aminopropyltriethoxysilane (APTES), hydrazine monohydrate, ethanol (EtOH), ammonia solution $\left(30 \% \mathrm{NH}_{4} \mathrm{OH}\right)$, hydrogen peroxide $\left(30 \% \mathrm{H}_{2} \mathrm{O}_{2}\right)$, O-(2-aminoethyl)polyethyleneglycol (average $M_{\mathrm{W}}=2000, \mathrm{PEG}_{34}$ ), human serum albumin (HSA), insulin, 1-pyrenecarboxylic acid (PCA), 1-pyrenebutanoic acid succinimidyl ester (PBSE), $N$-ethyl- $N^{\prime}-(3-$ dimethylaminopropyl)carbodiimide (EDC),
$N$-hydroxysuccinimide (NHS), $N, N^{\prime}$-disuccinimidyl carbonate $\left(\geq 95.0 \%\right.$, DSC), dichloromethane $\left(\geq 99.8 \%, \mathrm{CH}_{2} \mathrm{Cl}_{2}\right)$, and phosphate buffer tablets (PBS, $0.1 \mathrm{M}$ ) were purchased from Sigma-Aldrich and used as received. Graphene oxide (GO) powder was purchased from Graphenea, Spain.

Microelectrodes (ED-IDE1-Au w/o SU8) were purchased from Micrux Technologies, Spain.

The 5'-amine-modified HPV-16 E7 aptamer with spacer $\left(\mathrm{NH}_{2}-5^{\prime} \text {-(TTT) }\right)_{8}$ GGG AGG ACG AUG CGG AAG CAT CAA GGG TGA TCG TTT GAC CCT CCC CAG ACG ACU CGC CCG A-3) [18] was purchased from Integrated DNA Technologies (IDT Corporation).

The scrambled aptamer sequence used was $\mathrm{NH}_{2}-5^{\prime}-(\mathrm{TTT})_{8}$ GG GAG GAC GAU GCG GGT AAT AAA CAC GAC AAC GCT TTA TTG CCC CCA GAC GAC UCG CCC GA-3 (Integrated DNA Technologies, IDT Corporation).

The HPV recombinant HPV-16 E7 $\left(M_{\mathrm{W}}=15 \mathrm{kDa}\right)$ was obtained from LifeSpan BioSciences. Human insulin for control experiments was obtained from Sigma-Aldrich.

Saliva samples were kindly provided by the Centre Hospitalier Universitaire (CHU), Lille.

The blocking agent PEG was pre-conjugated with a PBSE linker (PyPEG) for later $\pi-\pi$ immobilization on the rGO surface [19].

\subsection{Fabrication of reduced graphene oxide-based FET}

Before modification with $\mathrm{rGO}$, the microelectrodes were cleaned by submerging them in a solution of 5 parts deionized water, 1 part ammonia solution $\left(30 \% \mathrm{NH}_{4} \mathrm{OH}\right)$, and 1 part hydrogen peroxide $\left(30 \% \mathrm{H}_{2} \mathrm{O}_{2}\right)$ and heating to $80^{\circ} \mathrm{C}$, followed by rinsing with deionized water and absolute $\mathrm{EtOH}$, before being blow-dried with compressed air, and stored for later use in a plastic Petri dish. Before graphene oxide (GO) transfer, the glass part between the interdigitated electrodes (IDE) was functionalized with 3-amino-propyltriethoxysilane (APTES) by using a $2 \%$ APTES in absolute EtOH for $1 \mathrm{~h}$, followed by rinsing with water and absolute $\mathrm{EtOH}$ to remove excess silane.

All chips are placed in a glass Petri dish and annealed at $120{ }^{\circ} \mathrm{C}$ for $2 \mathrm{~h}$. GO $\left(12.5 \mu \mathrm{g} \mathrm{mL}{ }^{-1}\right)$ was transferred to the silanized IDE by drop casting of $15 \mu \mathrm{L}$. After $2 \mathrm{~h}$, the excess GO suspension is rinsed off with deionized $\mathrm{dH}_{2} \mathrm{O}$ and carefully blow-dried with compressed air.

Reduction of GO to $\mathrm{rGO}$ was performed by placing the electrodes into a glass Petri dish and adding $1 \mathrm{~mL}$ of hydrazine into the corners of the glass dish, while the chips are all placed in the center. Immediately, the lid is sealed air-tight with Kapton tape right afterwards and the dish is placed in an oven inside the fume hood at $80^{\circ} \mathrm{C}$ for $4 \mathrm{~h}$. After reduction, the Petri dish remains in the fume hood without lid for $1 \mathrm{~h}$ to evaporate the remaining hydrazine before rinsing each chip with $\mathrm{dH}_{2} \mathrm{O}$ and subsequently with isopropanol to remove hydrazine 
residues, then gently blow-dry with nitrogen and store the chips in a desiccator or directly perform the thermal reduction. These slides were furthermore annealed at $200{ }^{\circ} \mathrm{C}$ under vacuum for $2 \mathrm{~h}$, resulting in stable and highly conducting electrical interfaces.

\subsection{Surface modification towards an HPV-16 E7 aptasensor}

The rGO-FET was immersed into a mixture of PyPEG $(5 \mathrm{mM})$ and 1-pyrenecarboxylic acid (PCA, $500 \mu \mathrm{M}$, linker) in DMSO for $12 \mathrm{~h}$ at room temperature to obtain a 10:1 ratio of blocking and linking agents and subsequently rinsed thoroughly with DMSO and $\mathrm{dH}_{2} \mathrm{O}$. Then, HPV-16 E7 aptamers were immobilized by first activating the carboxyl groups by immersion into a solution of EDC (15 mM)/NHS $(15 \mathrm{mM})$ in PBS (0.1 M, pH 7.4) for $30 \mathrm{~min}$, followed by covalent coupling of the $5^{\prime}-\mathrm{NH}_{2}$-modified aptamer $(15 \mu \mathrm{L}, 100 \mathrm{nM}$ in RNase-free water) by incubating for $40 \mathrm{~min}$ at room temperature and washing (3 times) with PBS.

\subsection{Characterization}

Scanning electron microscopy Scanning electron microscopy (SEM) images were obtained using an electron microscope ULTRA 55 (Zeiss, France) equipped with a thermal field emission emitter and three different detectors (EsB detector with filter grid, high-efficiency In-lens SE detector, and Everhart-Thornley secondary electron detector).

Micro-Raman analysis Micro-Raman spectroscopy measurements were performed on a LabRam HR micro-Raman system (Horiba Jobin Yvon, France) combined with a 473-nm laser diode as an excitation source. Visible light is focused by $\mathrm{a} \times$ 100 objective. The scattered light is collected by the same objective in backscattering configuration, dispersed by an 1800$\mathrm{mm}$ focal length monochromator and detected by a CCD.

X-ray photoelectron spectroscopy All measurements were carried out on a Thermo Fisher Microlab 310/350spectrometer equipped with a twin anode $\mathrm{Al} / \mathrm{Mg}-\mathrm{K} \alpha \mathrm{X}$-ray source (XR3) and a hemispherical analyzer. Samples were mounted onto the sample holders using double-sided carbon tape.

Pass energies of $100 \mathrm{eV}$ and $20 \mathrm{eV}$ as well as energy resolutions of $1 \mathrm{eV}$ and $100 \mathrm{meV}$ were used for survey and detail spectra respectively (excitation energy: $1486.6 \mathrm{eV} /$ $1253.6 \mathrm{eV}$, beam power: $100 \mathrm{~W}$, angle, base pressure: $3 \times$ $10^{-9}$ mbar, pressure during measurements: $7 \times 10^{-9} \mathrm{mbar}$ ). All measurements were carried out with the sample in normal emission angle with respect to the analyzer. The analysis area was around $7 \times 7 \mathrm{~mm}^{2}$. Data analysis was done using the CASA XPS and Thermo Fisher Avantage software packages employing Shirley/Tougaard backgrounds [20] and Scofield sensitivity factors [21]. Charge correction was applied to the spectra so the $\mathrm{C} 1 \mathrm{~s}$ signal of adventitious carbon was shifted to $284.6-284.8 \mathrm{eV}$ throughout the measurements. Curve fits using combined Gaussian-Lorentzian peak shapes (GL(0)-GL(70)) were used to discern the components.

\subsection{Electrical measurements}

Electrical measurements were conducted using a probe station source meter unit U2422A (Keysight Technologies, USA). All measurements were performed using a custom-made flow cell made of PMMA with fixed flow channel geometry $(16 \mu \mathrm{L})$, ensuring a defined flow rate of $100 \mu \mathrm{L} / \mathrm{min}$ to minimize mass transport limitation of the analyte to the sensor surface in all experiments. Furthermore, electrode drilling for constants gateelectrode distance $(100 \mu \mathrm{m})$ and a hollow with FET dimensions for fixed positioning of the sensor chip were incorporated to the flow cell. A silver chloride wire (diameter $1 \mathrm{~mm}$, Sigma-Aldrich) was used to operate the rGO-FET device in liquid gate configuration, with a constant gate bias of $-0.3 \mathrm{~V}$ and a constant source drain bias of $0.05 \mathrm{~V}$. The verification of the electrical signal was carried out on a surface plasmon resonance device Indicator-G (Sensia S.L.).

The general procedure of the sensing experiment started with continuously flushing the pure buffer (PBS, $1 \mathrm{mM}$ ) until a stable baseline of drain current was established, followed by injection of the analyte at a constant flow rate of $100 \mu \mathrm{L} \mathrm{min}{ }^{-1}$.

\subsection{Electrical output characteristics}

Electrical parameters of the rGO-FET were determined using gate-source voltage vs. drain-source current $\left(I_{\mathrm{D}} V_{\mathrm{G}}\right)$ relations. The charge carrier mobility $\mu$ (Eq. 1 ) was determined from the linear regime in the $I_{\mathrm{D}} V_{\mathrm{G}}$ graph according to Eq. 1 [22]:

$\mu=\frac{1}{\alpha e} \frac{d q}{d V}$

where $\alpha$ is the induced carrier density by the gate voltage $\left(V_{\mathrm{G}}\right)$ change of $1 \mathrm{~V}$ and $e$ is the electron charge. From the expression for the linear regimes in the $I_{\mathrm{D}} V_{\mathrm{G}}$ graph, the electron/hole mobility is obtained after considering the device properties according to Eq. 2:

$\mu_{\mathrm{eff}}=m_{\mathrm{lin}} \cdot \frac{L}{W \cdot V_{\mathrm{DS}} \cdot C_{i}}$

where $m_{\operatorname{lin}}$ is the slope from the linear fit (in $\mathrm{A} \mathrm{V}^{-1}$ ), $L$ and $W$ are the channel length and width (in $\mathrm{m}$ ), respectively, $V_{\mathrm{DS}}$ is 
the applied drain-source voltage (in $\mathrm{V}$ ), and $C_{\mathrm{i}}$ is the gate capacitance (in F). The values for $L, W$, and $C_{\mathrm{i}}$ are considered for the particular interdigitated electrodes and the designed flow cell. The geometric design of the IDE results in a channel length of $10 \mu \mathrm{m}$ and width of $490 \mathrm{~mm}$ over 90 parallel electrode pairs. The capacity $C_{\mathrm{i}}$ is $3.3 \mu \mathrm{F}$, evaluated from cyclic voltammetry measurements from the IDT to the gate electrode in the present flow cell design.

\section{Results and discussion}

\subsection{Fabrication of HPV-16 E7 sensitive rGO-FET}

The experimental setup of an individual rGO-FET device is shown in Fig. 1a. The interdigitated electrode chip with the functionalized rGO layer is placed into the sample holder and a sealed flow cell with inlet, outlet, and gating wire encloses the measurement chamber. The two terminals of the IDE and the gate electrode are electrically connected as shown in Fig. $1 \mathrm{~b}$ and the signal is recorded with the source meter unit U2722A (Keysight Technologies). While chemical vapordeposited graphene (CVD graphene) allows for the exact material positioning of high-quality graphene with little defects [23], the advantage of using liquid-dispersed graphene oxide (GO) flakes facilitates the fabrication but comes with the disadvantage of a practically random and uncontrolled distribution of the GO flakes, resulting in random localization during the adsorption from the liquid onto the gate surface. Figure 1c depicts an SEM image of the drain-source channel of the interdigitated electrodes (IDE) coated with rGO, where a full drain-source channel coverage can be observed. The dimensions of the IDE chip are $6 \mathrm{~mm}$ in width and $10 \mathrm{~mm}$ in length, with a circular sensing area of $3 \mathrm{~mm}$ in diameter. The rGO sheets, obtained by sequential GO transfer and 4-h hydrazine reduction [3], followed by thermal annealing, were further characterized by Raman microscopy. The Raman spectrum (Fig. 1d) consists of two main bands at 1597 and $1341 \mathrm{~cm}^{-1}$ related to $\mathrm{sp}^{2}$ carbon (graphenic) and defects in the rGO sheets

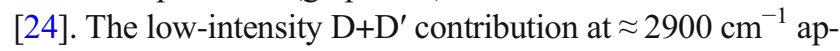
pears due to the impurities of rGO.

The surface characterization to validate the presence of rGO is documented in Fig. 2a, which shows a series of C1s high-resolution X-ray photoelectron spectroscopy (XPS) spectra of the transferred GO films before and after hydrazine/thermal annealing. The initial scan of GOdeposited films displays strong bands at 284.3, 285.0, and $286.7 \mathrm{eV}$, indicating the presence of both $\mathrm{sp}^{2} \mathrm{C}-\mathrm{C}, \mathrm{C}-\mathrm{C} / \mathrm{C}-$ $\mathrm{H}$, and $\mathrm{C}-\mathrm{O}$ bonds, respectively. The broad band at $288.3 \mathrm{eV}$ indicates the presence of $\mathrm{C}=\mathrm{O}$ groups. After reduction, a relative decrease in the intensity of the $\mathrm{C}-\mathrm{O}$ bonds is observed, along with a strong removal of the $\mathrm{sp}^{3} \mathrm{C}-\mathrm{C}$ component as would be expected as the carbon becomes more graphitic [25].

Electrical measurements of the rGO-FET are displayed in Fig. 2b. The drain-source current $\left(I_{\mathrm{DS}}\right)$ dependency to the gate voltage $\left(V_{\mathrm{G}}\right)$ of the rGO-FET can be seen in this
Fig. 1 Reduced graphene oxidebased FET (rGO-FET) used for HPV-16 E7 sensing. a Schematic image of the rGO-FET device. $\mathbf{b}$ Electrical measurement setup to record the gFET readout in liquid gate configuration. c Scanning electron microscopy (SEM) images of the drain-source channel of the interdigitated electrodes (IDE) upon coating with GO $\left(12.5 \mu \mathrm{g} \mathrm{mL}^{-1}\right)$ followed by reduction to rGO for $4 \mathrm{~h}$ in hydrazine vapor and post-annealing at $200{ }^{\circ} \mathrm{C}$ for $2 \mathrm{~h}$. $\mathbf{d}$ Raman spectra of GO and rGO-FET sensors a

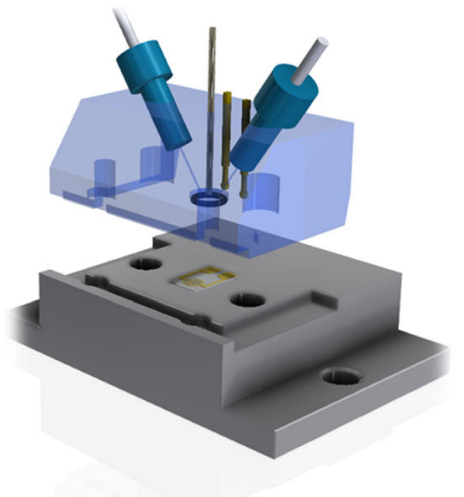

C

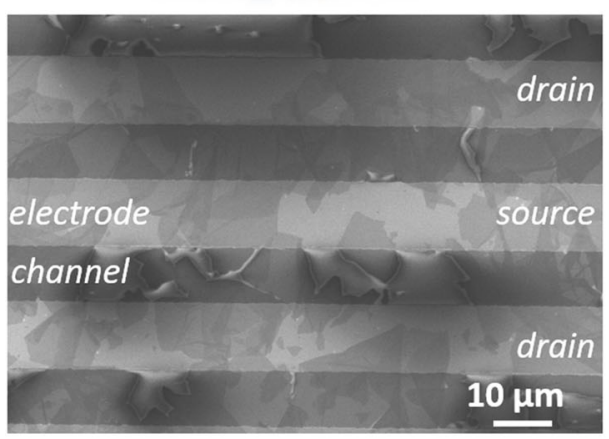

b

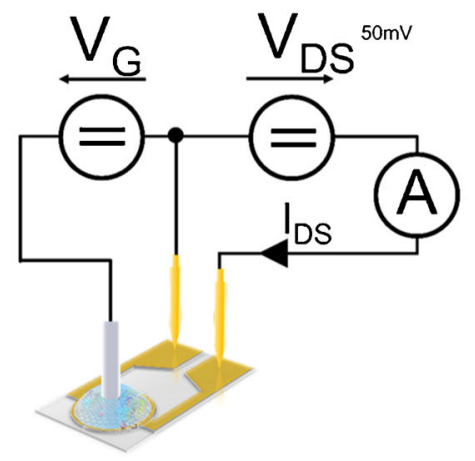

d

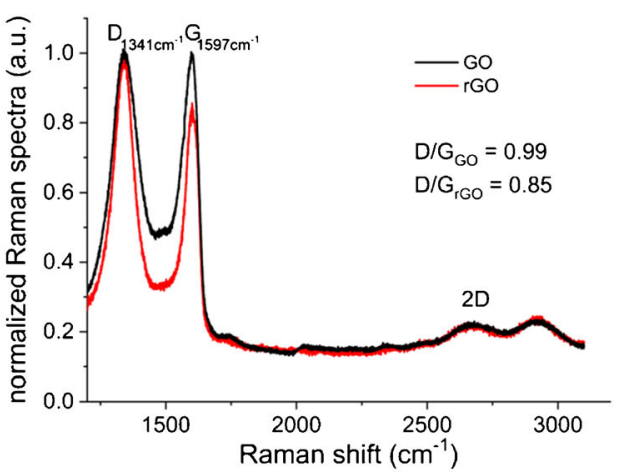


Fig. 2 Reduced graphene oxidebased FET (rGO-FET) used for HPV-16 E7 sensing. a XPS spectra of GO-FET before (top) and after (bottom) reduction, by treating the GO layer for $4 \mathrm{~h}$ with hydrazine followed by thermal annealing. b Transfer characteristics of a solution-gated rGO-FET before and after surface modification with a PCA linker, leading to a Dirac point shift of $50 \mathrm{mV}$

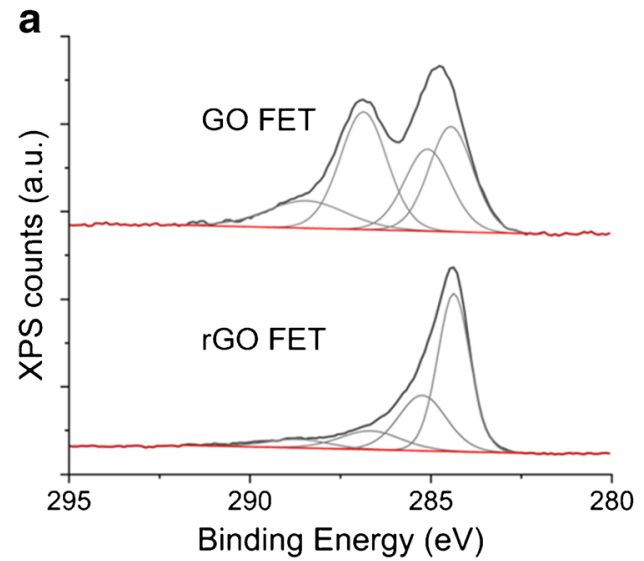

b

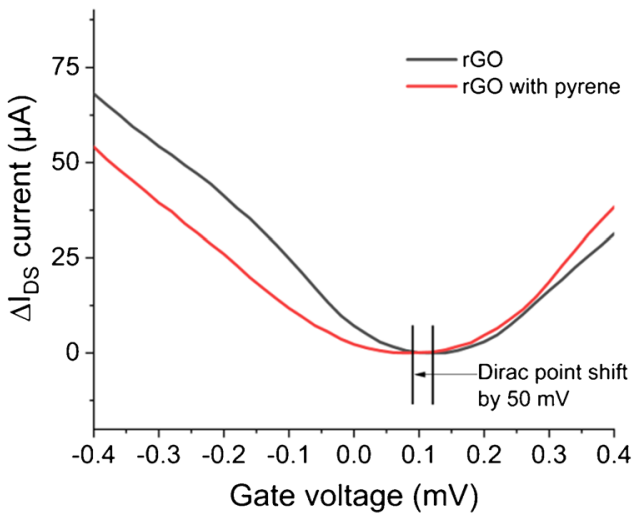

plot. The minimum of the current, the so-called Dirac point, is observed at $130 \mathrm{mV}$ before and at $80 \mathrm{mV}$ after the modification with the 1-pyrenecarboxylic acid linker.
The examined devices show an ambipolar nature, with a linear regime for both charge carrier types below $\pm 1 \mathrm{~V}_{\mathrm{G}}$ (Fig. $2 b)$. From the linear fit of the slopes negative and positive to
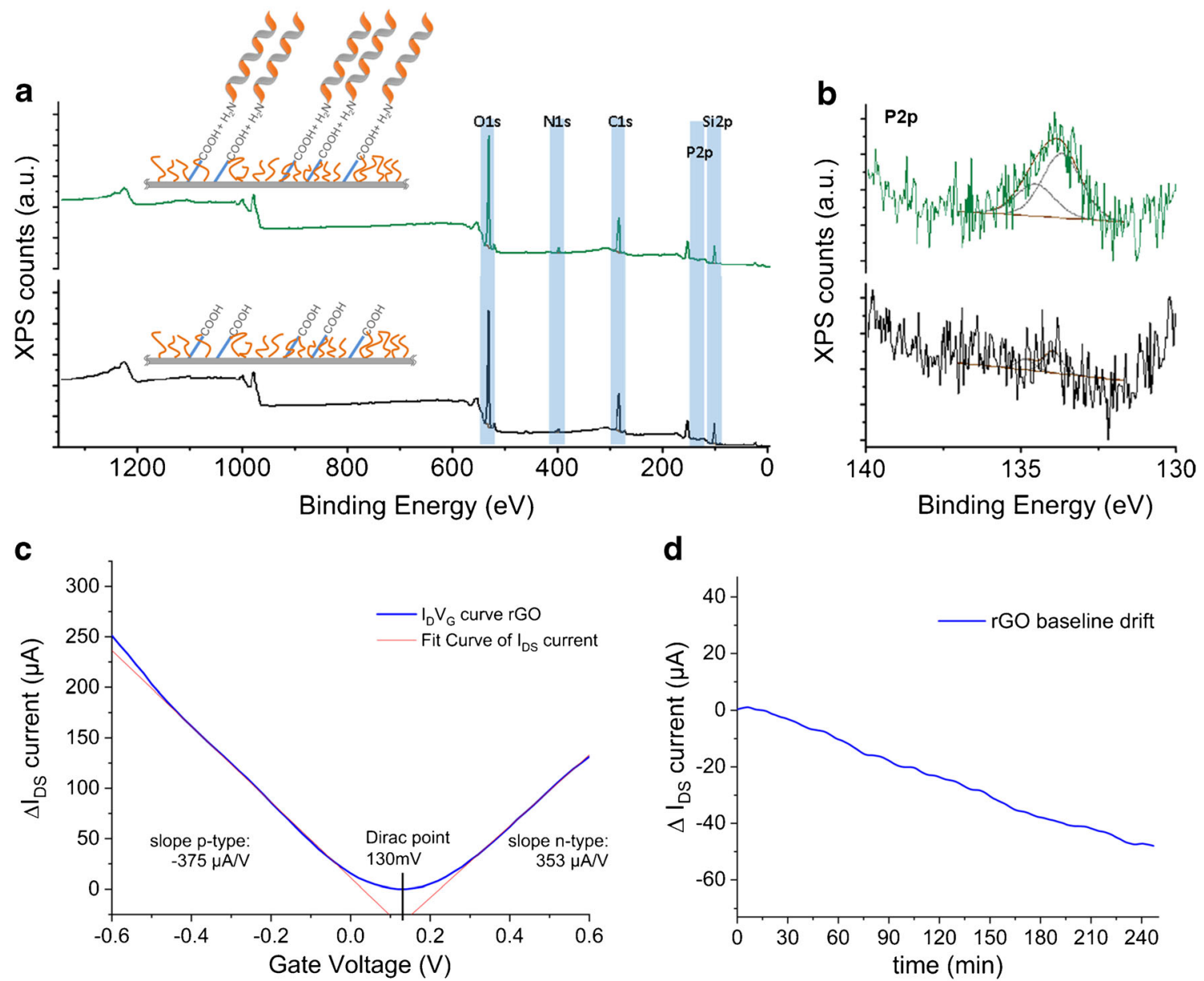

d

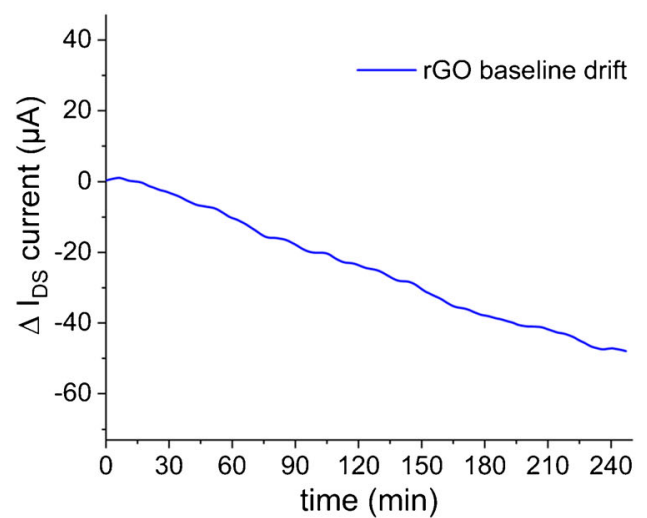

Fig. 3 Modification of the rGO-FET with RNA HVP-16 E7 aptamer. a XPS spectra of the rGO surface before and after modification with a pyrene linker for aptamer immobilization. Green represents the XPS spectrum of the aptamer-modified rGO surface, while the black spectrum corresponds to the surface functionalized with only PyPEG/PCA molecules. b High-resolution XPS spectra in the P2p region of the rGO surface

before and after aptamer immobilization to investigate the uptake of phosphate, present in the aptamer backbone. c Transfer characteristics of an HPV-16 E7 RNA aptamer-modified rGO-FET with the standard linker mixture of 10:1 PyPEG/PCA. d Change of the drain-source current $I_{\text {DS }}$ over time at an applied $V_{\mathrm{G}}=500 \mathrm{mV}$ in PBS $(0.1 \mathrm{M}, \mathrm{pH} 7.4)$ to demonstrate the baseline drift within $4 \mathrm{~h}$ of the modified gFET surface 

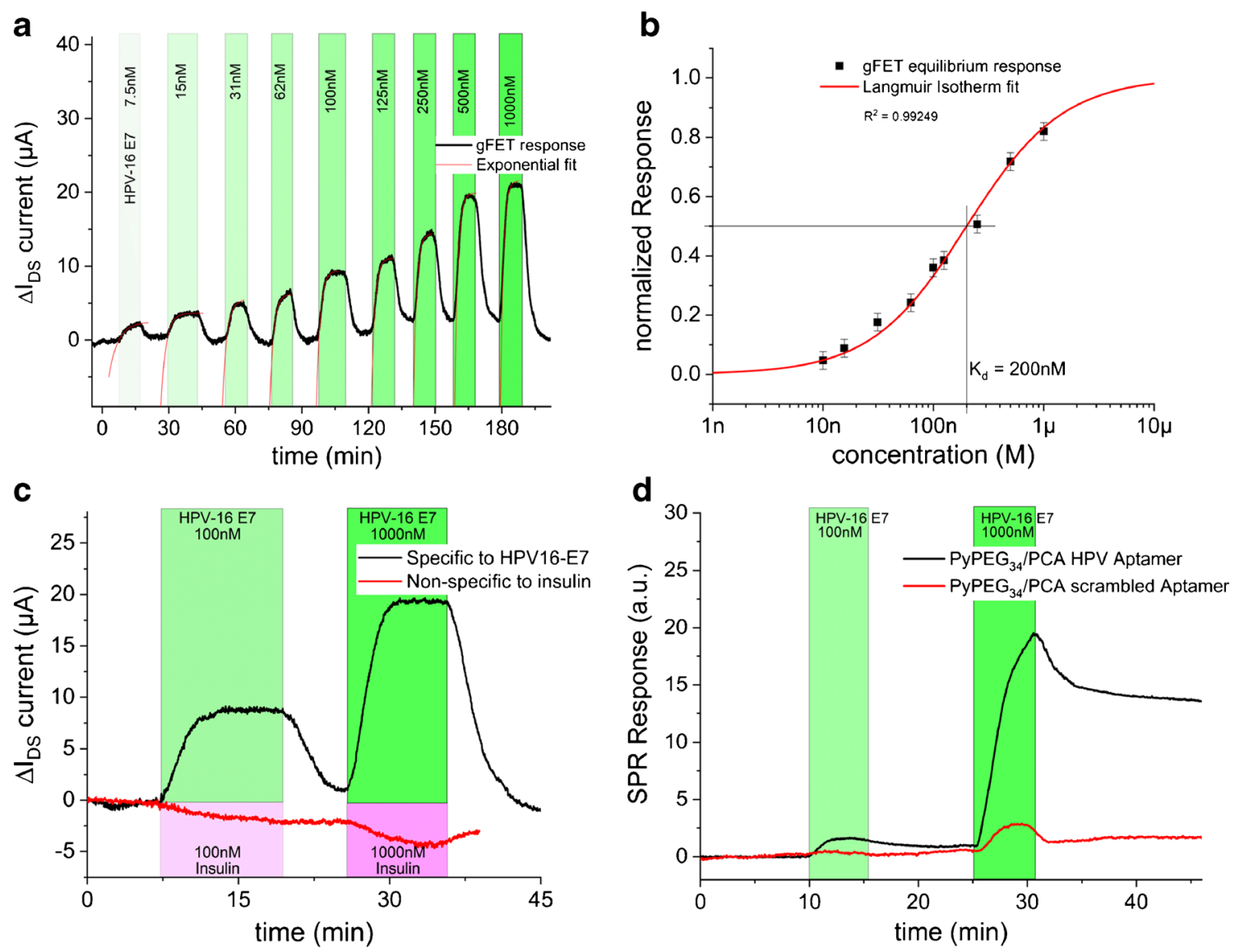

Fig. 4 FET-based sensing of HPV-16 E7 proteins. a Protein sensing in real time using aptamer-modified rGO-FET when the device is exposed to increasing concentrations of HPV-16 E7 proteins $(7.5,15,31,62,100$, $125,250,500$, and $1000 \mathrm{nM})$ in PBS $(0.1 \mathrm{M}, \mathrm{pH} 7.4)$. Additionally, insulin was exposed to the sensor surface to verify the blocking of nonspecific proteins. The aptasensor exhibits minute response to non-specific concentrations of $1 \mu \mathrm{M}$, proving the repelling due to the PyPEG coating of the sensing area. b Effective response extracted from the $I_{\mathrm{DS}}$ current,

the Dirac point, the charge carrier mobility was found in the range of $725 \mathrm{~cm}^{2}(\mathrm{Vs})^{-1}$ for electrons and $680 \mathrm{~cm}^{2}(\mathrm{Vs})^{-1}$ for the hole mobility for the rGO-FETs. The values are low, compared with previous reports $\left(5000 \mathrm{~cm}^{2}(\mathrm{Vs})^{-1}\right.$ [26] to $200.000 \mathrm{~cm}^{2}(\mathrm{Vs})^{-1}$ [27]), while others report low mobilities of $1 \mathrm{~cm}^{2}(\mathrm{Vs})^{-1}[28]$ in literature, but the absolute changes in current $I_{\mathrm{DS}}$ are by three orders of magnitude higher than other reports, hence yield a better signal-to-noise ratio.

\subsection{Surface modification of rGO-FET for HPV-16 E7 sensing}

To create a functional surface for preferential HPV-16 E7 binding, the rGO-FET chip was functionalized with 1-pyrenebutyric acid (PCA), followed by EDC/NHS activation for covalent linking of the aptamer comprising an $\mathrm{NH}_{2}$ end group and a spacer of eight repetitions of TTT units. The success of the surface functionalization was assessed using XPS (Fig. 3a).

generated by different HPV-16 E7 protein concentrations and fitted to a Langmuir isotherm. The $K_{\mathrm{d}}$ at half saturation equals $200 \mathrm{nM}$. c Signal generation of an aptamer unfolding upon specific binding to HPV-16 E7 (black) compared with non-specific binding of insulin to the surface. $\mathbf{d}$ SPR experiments using HPV aptamer (black) and scrambled aptamer (red) surface linker incorporated in the same manner as on the rGOFET sensors to investigate the specificity of the aptamers for HPV-16 E7 sensing

The PCA was mixed with a blocking agent of pre-conjugated pyrene-PEG units (PyPEG) in a ratio of 1:10, a ratio experimentally verified to be optimal for having an anti-fouling character and good sensing sensitivity (Fig. 3a inset). It was reported that this RNA E7 aptamer has an affinity with a low dissociation constant $K_{\mathrm{d}}=2 \mu \mathrm{M}$ [29]. This indicates that the sensor is in the ligand-depletion regime, where experimental conditions, including probe density and surface area as well as sample volume, are important parameters [30]. The success of the surface modification steps was validated by XPS analysis (Fig. $3 b$ ), with the presence of phosphate after RNA immobilization. The $I_{\mathrm{DS}}$ vs. $V_{\mathrm{G}}$ curves of the aptamer-functionalized device are shown in Fig. 3c. The Dirac point after RNA immobilization is stabilized at $130 \pm 10 \mathrm{mV}$ vs. $\mathrm{AgCl}$ wire without affecting the transconductance with the addition of PCA via non-covalent $\pi-\pi$ stacking interactions.

Next to the electrical transfer characteristic of the rGO-FET device after aptamer immobilization, the baseline drift over 
time is an important parameter for any sensor application. Figure $3 \mathrm{~d}$ shows a minute drift with approximately $50 \mu \mathrm{A} /$ $4 \mathrm{~h}$. Due to the linear characteristic of the current decay in the observed time frame, it can be corrected with a linear regression after an established baseline. The baseline was subtracted from the recorded sensor output to obtain the sensing response, $\Delta I_{\mathrm{DS}}$.

\subsection{Specific sensing of HPV-16 E7}

The functionalized rGO-FET devices were used to electronically monitor aptamer-protein binding in real time by exposing it to increasing concentrations of HPV recombinant HPV-16 E7 protein (Fig. 4a). A large change in current is observed for the target solution due to preferential binding of the protein to the aptamer. The equilibrium value and the kinetic on- and off-rates are useful parameters for determining the dissociation constant $K_{\mathrm{d}}$ of the binding reaction. Figure $4 \mathrm{~b}$ illustrates the saturation levels of the aptasensor for different concentrations, normalized to its maximum possible response, when all binding sites are occupied, and the binding curve follows a Langmuir isotherm model (Eq. 3).

$\Delta I_{\mathrm{DS}}{ }^{\mathrm{equ}}=\Delta I_{\mathrm{DS}}{ }^{\text {mass }} \cdot \frac{[\mathrm{HPV}-16 \mathrm{E} 7]}{[\mathrm{HPV}-16 \mathrm{E} 7]+K_{\mathrm{d}}}$

Fitting Eq. 3 to the data points yields a $K_{\mathrm{d}}$ of $200 \mathrm{nM}$ at half saturation, consistent with previous reports of aptamer-protein binding reactions.

To underline specific binding, the change in electrical signal upon binding to insulin, a protein of comparable size, was recorded at comparable concentrations (Fig. 4c). The addition of $100 \mathrm{nM}$ and $1000 \mathrm{nM}$ insulin leads to a minute gFET response. The net charge of insulin is negative at a $\mathrm{pH}$ of 7.4 due to the isoelectric point at 5.3 [31]. Upon non-specific interaction with the surface, it increases the negative charge at the semiconductor surface and counteracts the applied electric field. On the other hand, the electric field will increase upon specific binding of the aptamer to HPV-16 E7 proteins, due to the conformational change and increased distance of the negatively charged RNA from the surface $[32,33]$.

Additionally, the titration of the HPV-16 E7 protein was performed on a graphene surface in an optical measurement device (SPR) with a scrambled aptamer sequence (Fig. 4d). The response of the surface plasmon resonance experiment on graphene-coated gold substrates indicates that the aptamer is specifically binding to the protein, while the scrambled sequence shows minute non-specific interactions at $1000 \mathrm{nM}$.

The detection limit for the E7 protein was determined to be about $1.75 \mathrm{nM}\left(100 \mathrm{pg} \mathrm{mL}^{-1}\right)$ from five blank noise signals (95\% confidence level) in PBS (Fig. 5). The eventual feasibility of the use of the sensor in biological relevant media was evaluated by establishing a calibration curve of E7 protein in saliva samples spiked with different concentrations of E7. Indeed, one widely accepted detection scenario is based on HPV-16 E7 detection in saliva [34]. Saliva, which is $90.5 \%$ composed of water, is in addition composed of a variety of electrolytes, including sodium, potassium, calcium, magnesium, chloride, bicarbonate, and phosphate. It also contains immunoglobulins, enzymes, mucus, and proteins. The calibration curves in PBS and spiked saliva are shown in Fig. 5. Both curves are comparable, with a minute reduction in sensitivity. The response to HPV-16 E7 in spiked saliva decreased due to increased ion concentrations in saliva, reducing the Debye length for the biorecognition in real time [35]. The linear regime of the sensor remains and is suitable for biosensing applications, and the signal is reduced by approximately $9 \%$ compared with PBS buffer.

The reproducibility of the electrode fabrication and use for HPV-16 E7 sensing is expressed in terms of the relative standard deviation and is found to be $9.3 \%$ at HPV-16 E7 concentration of $1 \mathrm{ng} \mathrm{mL}{ }^{-1}$. The long-term stability of the sensor exhibited a loss of 5\% when tested in HPV-16 E7 $\left(1 \mathrm{ng} \mathrm{mL}{ }^{-1}\right.$ ) after the electrode was stored at $4{ }^{\circ} \mathrm{C}$ for a month.

\section{Conclusion}

In conclusion, sensing on reduced graphene oxide-modified FET of HPV-16 E7 protein was demonstrated. An important aspect in any sensing device is the way the ligand is attached to the interface. In our case, integration of a HPV-16 E7-

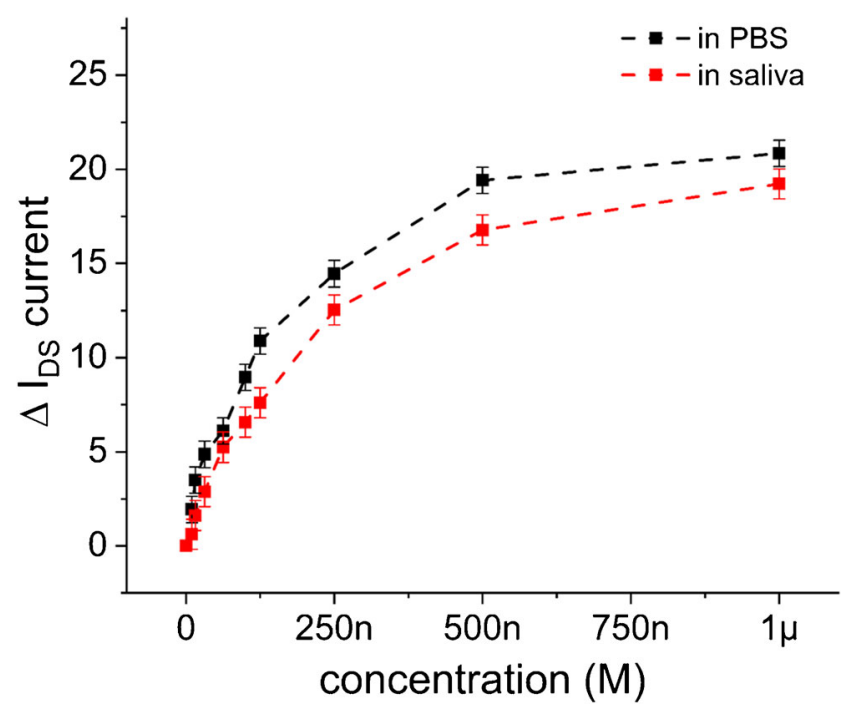

Fig. 5 Sensing characteristics of gFET for HPV-16 E7 proteins. Calibration curve of the HPV-16 E7 protein sensor in PBS (black) and in saliva (red). Protein sensing in real time using aptamer-modified rGOFET when the device is exposed to increasing concentrations of HPV-16 E7 proteins $(7.5,15,31,62,100,125,250,500$, and $1000 \mathrm{nM})$ 
specific aptamer was achieved by covalent EDC/NHS coupling to rGO-FET pre-modified with 1-pyrenebutyric acid/ pyrene-PEG in a ratio of 1:10. Monitoring the aptamerprotein binding in real time revealed preferential binding of HPV-16 E7 with a detection limit of about $100 \mathrm{pg} \mathrm{mL}^{-1}$ $(1.75 \mathrm{nM})$ for HPV-16 E7 from five blank noise signals (95\% confidence level). The dissociation constant $K_{\mathrm{d}}$ of the binding reaction was determined as $200 \mathrm{nM}$, consistent with previous reports of aptamer-protein binding reactions.

Acknowledgments XPS measurements performed by TU Wien, Analytical Instrumentation Center (aic), Annette Foelske-Schmitz, and Markus Sauer, Getreidemarkt 9/BL01A01, 1060 Vienna, Austria, are gratefully acknowledged.

Funding information Financial support from the Centre National de la Recherche Scientifique (CNRS), the University of Lille, the Hauts-deFrance region, the CPER "Photonics for Society", and the joint support of Agence Nationale de la Recherche (ANR) through FLAG-ERA JTC 2015-Graphtivity project are acknowledged. Financial support came further from the FFG, Austria, within the Comet program, and from the governments of Lower and Upper Austria.

\section{Compliance with ethical standards}

Conflict of interest The authors declare that they have no conflict of interest.

\section{References}

1. Stine R, Robinson JT, Sheehan PE, Tamanaha CR. Real-time DNA detection using reduced graphene oxide field effect transistors. Adv Mater. 2010;22:5297-300. https://doi.org/10.1002/adma. 201002121.

2. Cai B, Wang S, Huang L, Ning Y, Zhang Z, Zhang G-J. Ultrasensitive label-free detection of PNA-DNA hybridization by reduced graphene oxide field-effect transistor biosensor. ACS Nano. 2014;8:2632-8. https://doi.org/10.1021/nn4063424.

3. Reiner-Rozman C, Larisika M, Nowak C, Knoll W. Graphenebased liquid-gated field effect transistor for biosensing: theory and experiments. Biosens Bioelectron. 2015;70:21-7. https://doi. org/10.1016/j.bios.2015.03.013.

4. Chen Y, Ren R, Pu H, Guo X, Chang J, Zhou G, et al. Field-effect transistor biosensor for rapid detection of Ebola antigen. Sci Rep. 2017;7:10974. https://doi.org/10.1038/s41598-017-11387-7.

5. Bustin SA, Mueller R. Real-time reverse transcription PCR (qRTPCR) and its potential use in clinical diagnosis. Clin Sci. 2005;109: 365-79. https://doi.org/10.1042/CS20050086.

6. Hayden RT, Gu Z, Rodriguez A, Tanioka L, Ying C, Morgenstern $\mathrm{M}$, et al. Comparison of two broadly multiplexed PCR systems for viral detection in clinical respiratory tract specimens from immunocompromised children. J Clin Virol. 2012;53:308-13. https://doi. org/10.1016/j.jcv.2011.12.020.

7. Liu F, Kim YH, Cheon DS, Seo TS. Micropatterned reduced graphene oxide based field-effect transistor for real-time virus detection. Sensors Actuators B Chem. 2013;186:252-7. https://doi. org/10.1016/j.snb.2013.05.097.

8. Chan C, Shi J, Fan Y, Yang M. A microfluidic flow-through chip integrated with reduced graphene oxide transistor for influenza virus gene detection. Sensors Actuators B Chem. 2017;251:92733. https://doi.org/10.1016/j.snb.2017.05.147.

9. Afsahi S, Lerner MB, Goldstein JM, Lee J, Tang X, Bagarozzi DA, et al. Novel graphene-based biosensor for early detection of Zika virus infection. Biosens Bioelectron. 2018;100:85-8. https://doi. org/10.1016/j.bios.2017.08.051.

10. Islam S, Shukla S, Bajpai VK, Han Y-K, Huh YS, Kumar A, et al. A smart nanosensor for the detection of human immunodeficiency virus and associated cardiovascular and arthritis diseases using functionalized graphene-based transistors. Biosens Bioelectron. 2019;126:792-9. https://doi.org/10.1016/j.bios.2018.11.041.

11. Seo G, Lee G, Kim MJ, Baek S-H, Choi M, Ku KB, et al. Rapid detection of COVID-19 causative virus (SARS-CoV-2) in human nasopharyngeal swab specimens using field-effect transistor-based biosensor. ACS Nano. 2020;14:5135-42. https://doi.org/10.1021/ acsnano.0c02823.

12. Boubriak OA, Soldatkin AP, Starodub NF, Sandrovsky AK, El'skaya AK. Determination of urea in blood serum by a urease biosensor based on an ion-sensitive field-effect transistor. Sensors Actuators B Chem. 1995;27:429-31. https://doi.org/10.1016/09254005(94)01633-S.

13. Schiffman M, Wentzensen N. Human papillomavirus infection and the multistage carcinogenesis of cervical cancer. Cancer Epidemiol Prev Biomark. 2013;22:553-60. https://doi.org/10.1158/10559965.EPI-12-1406.

14. Abreu ALP, Souza RP, Gimenes F, Consolaro MEL. A review of methods for detect human papillomavirus infection. Virol J. 2012;9:262. https://doi.org/10.1186/1743-422X-9-262.

15. Civit L, Fragoso A, O’Sullivan CK. Electrochemical biosensor for the multiplexed detection of human papillomavirus genes. Biosens Bioelectron. 2010;26:1684-7. https://doi.org/10.1016/j.bios.2010. 06.072 .

16. Wang S, Li L, Jin H, Yang T, Bao W, Huang S, et al. Electrochemical detection of hepatitis B and papilloma virus DNAs using SWCNT array coated with gold nanoparticles. Biosens Bioelectron. 2013;41:205-10. https://doi.org/10.1016/j. bios.2012.08.021.

17. Chekin F, Bagga K, Subramanian P, Jijie R, Singh SK, Kurungot S, et al. Nucleic aptamer modified porous reduced graphene oxide/ MoS2 based electrodes for viral detection: application to human papillomavirus (HPV). Sensors Actuators B Chem. 2018;262: 991-1000. https://doi.org/10.1016/j.snb.2018.02.065.

18. Gourronc FA, Rockey WM, Thiel WH, Giangrande PH, Klingelhutz AJ. Identification of RNA aptamers that internalize into HPV-16 E6/E7 transformed tonsillar epithelial cells. Virology. 2013;446:325-33. https://doi.org/10.1016/j.virol.2013. 08.015 .

19. Liu J, Bibari O, Mailley P, Dijon J, Rouvière E, Sauter-Starace F, et al. Stable non-covalent functionalisation of multi-walled carbon nanotubes by pyrene-polyethylene glycol through $\pi-\pi$ stacking. New J Chem. 2009;33:1017-24. https://doi.org/10.1039/ B813085J.

20. Tougaard S. Universality classes of inelastic electron scattering cross-sections. Surf Interface Anal. 1997;25:137-54. https://doi. org/10.1002/(SICI)1096-9918(199703)25:3<137::AID-SIA230>3. $0 . \mathrm{CO} ; 2-\mathrm{L}$

21. Scofield JH. Hartree-Slater subshell photoionization cross-sections at 1254 and $1487 \mathrm{eV}$. J Electron Spectrosc Relat Phenom. 1976;8: 129-37. https://doi.org/10.1016/0368-2048(76)80015-1.

22. Tanaka S, Goto H, Tomori H, Ootuka Y, Tsukagoshi K, Kanda A. Effect of current annealing on electronic properties of multilayer graphene. J Phys Conf Ser. 2010;232:012015. https://doi.org/10. 1088/1742-6596/232/1/012015.

23. Obraztsov AN, Volkov AP, Nagovitsyn KS, Nishimura K, Morisawa K, Nakano Y, et al. CVD growth and field emission 
properties of nanostructured carbon films. J Phys D Appl Phys. 2002;35:357-62. https://doi.org/10.1088/0022-3727/35/4/311.

24. Guerrero-Contreras J, Caballero-Briones F. Graphene oxide powders with different oxidation degree, prepared by synthesis variations of the Hummers method. Mater Chem Phys. 2015;153:20920. https://doi.org/10.1016/j.matchemphys.2015.01.005.

25. Leiro JA, Heinonen MH, Laiho T, Batirev IG. Core-level XPS spectra of fullerene, highly oriented pyrolitic graphite, and glassy carbon. J Electron Spectrosc Relat Phenom. 2003;128:205-13. https://doi.org/10.1016/S0368-2048(02)00284-0.

26. Lemme MC, Echtermeyer TJ, Baus M, Szafranek BN, Bolten J, Schmidt M, et al. Mobility in graphene double gate field effect transistors. Solid State Electron. 2008;52:514-8. https://doi.org/ 10.1016/j.sse.2007.10.054.

27. Bolotin KI, Sikes KJ, Jiang Z, Klima M, Fudenberg G, Hone J, et al. Ultrahigh electron mobility in suspended graphene. Solid State Commun. 2008;146:351-5. https://doi.org/10.1016/j.ssc.2008.02. 024.

28. Castro EV, Ochoa H, Katsnelson MI, Gorbachev RV, Elias DC, Novoselov KS, et al. Limits on charge carrier mobility in suspended graphene due to flexural phonons. Phys Rev Lett. 2010;105: 266601. https://doi.org/10.1103/PhysRevLett.105.266601.

29. Toscano-Garibay JD, Benítez-Hess ML, Alvarez-Salas LM. Isolation and characterization of an RNA aptamer for the HPV-16 E7 oncoprotein. Arch Med Res. 2011;42:88-96. https://doi.org/10. 1016/j.arcmed.2011.02.005.
30. Esteban Fernández de Ávila B, Watkins HM, Pingarrón JM, Plaxco KW, Palleschi G, Ricci F. Determinants of the detection limit and specificity of surface-based biosensors. Anal Chem. 2013;85:65937. https://doi.org/10.1021/ac4012123.

31. Wintersteiner $\mathrm{O}$, Abramson HA. The isoelectric point of insulin electrical properties of adsorbed and crystalline insulin. J Biol Chem. 1933;99:741-53.

32. Nakatsuka N, Yang K-A, Abendroth JM, Cheung KM, Xu X, Yang $\mathrm{H}$, et al. Aptamer-field-effect transistors overcome Debye length limitations for small-molecule sensing. Science. 2018;362:319-24. https://doi.org/10.1126/science.aao6750.

33. Aspermair P, Ramach U, Lechner B, Fossati S, Azzaroni O, Dostalek J, Szunerits S, Knoll W, Bintinger J Dual monitoring of surface reactions in real-time by combined surface-plasmon resonance and field-effect transistor interrogation. 5

34. Wai KC, Strohl MP, van Zante A, Ha PK. Molecular diagnostics in human papillomavirus-related head and neck squamous cell carcinoma. Cells. 2020;9:500. https://doi.org/10.3390/cells9020500.

35. Chu C-H, Sarangadharan I, Regmi A, Chen Y-W, Hsu C-P, Chang $\mathrm{W}-\mathrm{H}$, et al. Beyond the Debye length in high ionic strength solution: direct protein detection with field-effect transistors (FETs) in human serum. Sci Rep. 2017;7:5256. https://doi.org/10.1038/ s41598-017-05426-6.

Publisher's note Springer Nature remains neutral with regard to jurisdictional claims in published maps and institutional affiliations. 